\title{
Preoperative Plasma Levels of Total Testosterone Associated with High Grade Pathology-Detected Prostate Cancer: Preliminary Results of a Prospective Study in a Contemporary Cohort of Patients
}

\author{
Antonio B. Porcaro ${ }^{\mathrm{a}} \quad$ Nicolò De Luyk $^{\mathrm{a}}$ Paolo Corsi ${ }^{\mathrm{a}} \quad$ Marco Sebben $^{\mathrm{a}} \quad$ Alessandro Tafuria $^{\mathrm{a}}$ \\ Giovanni Cacciamani ${ }^{\mathrm{a}} \quad$ Davide De Marchi $^{\mathrm{a}} \quad$ Irene Tamanini $^{\mathrm{a}} \quad$ Davide Inverardi $^{\mathrm{a}}$ \\ Matteo Brunellib Maria A. Cerruto ${ }^{a} \quad$ Gian L. Salvagno $^{c} \quad$ Gian C. Guidic $^{c}$ Walter Artibani ${ }^{a}$

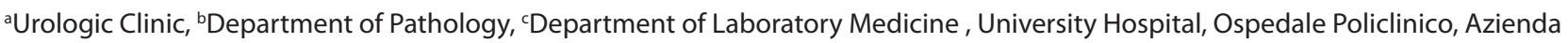 \\ Ospedaliera Universitaria Integrata, Verona, Italy
}

\section{Key Words}

Testosterone - Robot assisted radical prostatectomy • Retropubic radical prostatectomy • Prostate cancer • Hyptothalamus-pituitary-testis-prostate axis

\begin{abstract}
Objectives: To investigate the associations, if any, between preoperative plasma levels of total testosterone (TT) and pathology Gleason score ( $\mathrm{pGS}$ ) in a contemporary cohort of prostate cancer (PCa) patients. Materials and Methods: Between November 2014 and June 2015, plasma levels of TT were measured in 142 patients who underwent radical prostatectomy. Exclusion criteria were as follows: 5a-reductase inhibitors, LH-releasing hormone analogues, or testosterone replacement treatment. The entire cohort, assessed by continuous and categorical variables, was classified into two groups according to the $\mathrm{pGS}$ that included low-intermediate (pGS 6-7) and high grade (pGS > 7) cases. TT was evaluated as a continuous variable. Results: The cohort included 128 cases. High grade PCa was detected in 28 (21.8\%) patients. Median plasma levels of both TT and prostate specific anti-
\end{abstract}

\section{KARGER}

(C) 2016 S. Karger AG, Basel

Fax +4161306 1234

E-Mail karger@karger.com

www.karger.com
Accessible online at: www.karger.com/cur gen (PSA) were significantly higher in these cases. In the clinical multivariate model, independent and positive predictors of $\mathrm{pGS}>7$ were TT $(p=0.041 ; \mathrm{OR}=1.004), \mathrm{PSA}(\mathrm{p}=0.006$; OR $=1.191)$, and $b G S>6(p=0.004 ; O R=5.0)$; that is, a single unit increase in TT plasma levels increases the odds of having high grade PCa by $4 \%$. Conclusion: In a contemporary cohort of patients, preoperative plasma levels of TT directly and independently associated with high grade PCa. High baseline plasma levels of TT might have clinical applications for managing PCa. New and well designed prospective studies dealing with this subject are required.

Copyright $\odot 2016$ S. Karger AG, Basel

\section{Introduction}

Prostate biology is closely related to the hypothalamus-pituitary-adrenal-testis axis. In the testis, Leydig's interstitial cells are responsible for the production of $95 \%$ of all circulating androgen in the form of testos-

Antonio B. Porcaro,

Azienda Ospedaliera Universitaria Integrata Verona,

Dipartimento ad Attività Integrata di Chirurgia ED Oncologia - Pancreas Center,

Divisione Clinicizzata Di Urologia, Policlinico GB Rossi - P.le LA Scuro, 10

IT-37134, Verona (Italy)

E-Mail drporcaro@yahoo.com 
terone. Prostate physiology is regulated by androgens, estrogens, and pituitary hormones. Physiopathology factors related to the natural history of prostate cancer (PCa) are still unknown. Since the pioneering work of Charles Higgins [1], androgens have been universally considered pivotal in the regulation of normal function and malignant growth of the prostate. The pathophysiology of $\mathrm{PCa}$ is related to total testosterone (TT) and prostate-specific antigen (PSA) [1-3]. In the PCa population, abnormal pretreatment plasma levels of TT have been detected [4-7]. It has been postulated that PCa might produce a substance that alters the normal function of the pituitarytesticular-prostate axis which responds with abnormal LH and FSH serum levels [4-11]. It has also been suggested that the impact of $\mathrm{PCa}$ on the hypothalamic-pituitary-testis-prostate axis may be more profound in highgrade tumors [11]; however, the hypothesis has not been confirmed [12].

The pathology Gleason score (pGS) is the most effective predictor of PCa natural history (biochemical recurrence, development of metastases, and disease specific mortality) after treatment [13-16]. The association between pretreatment TT plasma levels and pGS is a main topic that still remains controversial, unsettled [4-7, 1012, 17-29], and requires further research [30].

In a cohort of patients we have shown that increased preoperative TT plasma levels independently associated with high grade $\mathrm{PCa}$ as coded by pGS $[31,32]$. The aim of the present study was to investigate the associations, if any, between preoperative plasma levels of TT and pGS in a new and contemporary cohort of patients.

\section{Materials and Methods}

Between November 2014 and June 2015, plasma levels of TT were measured in 142 consecutive patients who underwent radical prostatectomy (RP) by robot assisted or retropubic approach with or without extended lymph node dissection when appropriate. The study is part of a larger trial of PCa biobanking which has already been approved by the local Ethical Committee. An informed signed consent was obtained in all cases. The data were prospectively collected and retrospectively reviewed. Total testosterone was checked in the preoperative period, and it was done for research of a prospective study aiming at evaluating association between testosterone and prostate cancer. Exclusion criteria were as follows: 5 -reductase inhibitors, LH-releasing hormone analogues, or testosterone replacement treatment.

The 14-core transrectal ultrasound (TRUS) guided prostate biopsy technique was routinely used and additional cores were taken when a lesion on either TRUS or digital rectal examination was evident. Prostate volume (PV, ml) was measured by standard methods and PSA density (PSAD) was calculated. In PCa cases,

Preoperative Total Testosterone Serum

Levels and High Grade Prostate Cancer
Table 1. Clinical and pathological characteristics of the study cohort $(n=128)$

\begin{tabular}{|c|c|}
\hline Variables & Statistics \\
\hline \multicolumn{2}{|c|}{ Continuous (median, range) } \\
\hline Age (years) & $64.5(51-76)$ \\
\hline BMI (kg/m2) & $26.7(19.6-42.2)$ \\
\hline $\mathrm{TT}$ (ng/dl) & $331.5(116-814)$ \\
\hline PSA (ng/ml) & $7.5(0.7-25.9)$ \\
\hline $\mathrm{PV}(\mathrm{ml})$ & $40(15-105.0)$ \\
\hline $\mathrm{P}+$, proportion & $0.33(0.06-1.0)$ \\
\hline PSAD,$(\mathrm{ng} / \mathrm{ml}) / \mathrm{ml}$ & $0.19(0.01-0.84)$ \\
\hline \multicolumn{2}{|l|}{ Categorical $(\mathrm{n}, \%)$} \\
\hline \multicolumn{2}{|l|}{ RP } \\
\hline RARP & $98(76.6 \%)$ \\
\hline RRP & $30(23.4 \%)$ \\
\hline \multicolumn{2}{|l|}{ LND (n, \%) } \\
\hline no & $79(61.7 \%)$ \\
\hline yes & $49(38.3 \%)$ \\
\hline \multicolumn{2}{|l|}{$\mathrm{cT}(\mathrm{n}, \%)$} \\
\hline $1 \mathrm{c}$ & $100(78.1 \%)$ \\
\hline 2 & $26(20.3 \%)$ \\
\hline 3 & $2(1.6 \%)$ \\
\hline \multicolumn{2}{|l|}{ bGS (n, \%) } \\
\hline 6 & $61(47.7 \%)$ \\
\hline 7 & $58(45.3 \%)$ \\
\hline$>7$ & $9(7 \%)$ \\
\hline \multicolumn{2}{|l|}{ pGS (n, \%) } \\
\hline 6 & $23(18 \%)$ \\
\hline 7 & $77(60.2 \%)$ \\
\hline$>7$ & $28(21.8 \%)$ \\
\hline \multicolumn{2}{|l|}{$\mathrm{pT}(\mathrm{n}, \%)$} \\
\hline $2 a-b$ & $13(10.2 \%)$ \\
\hline $2 \mathrm{c}$ & $86(67.2 \%)$ \\
\hline $3 a$ & $15(11.7 \%)$ \\
\hline $3 b$ & $14(10.9 \%)$ \\
\hline \multicolumn{2}{|l|}{$\mathrm{pN}(\mathrm{n}, \%)$} \\
\hline 0 & $45(35.2 \%)$ \\
\hline 1 & $6(4.7 \%)$ \\
\hline $\mathrm{x}$ & $77(60.2 \%)$ \\
\hline \multicolumn{2}{|l|}{$\mathrm{SM}(\mathrm{n}, \%)$} \\
\hline$(-)$ & $96(75 \%)$ \\
\hline$(+)$ focal & $16(12.5 \%)$ \\
\hline (+) multifocal & $16(12.5 \%)$ \\
\hline
\end{tabular}

$\mathrm{BMI}=$ Body mass index $; \mathrm{TT}=$ total testosterone; $\mathrm{PV}=$ prostate volume; $\mathrm{P}+=$ proportion of biopsypositive cores; PSAD = PSA density; RP = radical prostatectomy (robotic: RARP; open: RRP); LND = lymph node dissection; $\mathrm{cT}=$ clinical tumor stage; bGS = biopsy Gleason score; $\mathrm{pGS}$ = pathology Gleason score; $\mathrm{pT}$ = tumour pathologic stage $; \mathrm{pN}=$ pathologic nodal stage; $\mathrm{SM}=$ surgical margins.

the biopsy Gleason score (bGS ) and proportion of positive cores $(\mathrm{P}+)$ were computed. Age (years) and body mass index (BMI, kg/ $\left.\mathrm{m}^{2}\right)$ were also determined. 
Table 2. Clinical and pathological characteristics of the cohort stratified by tumour grade

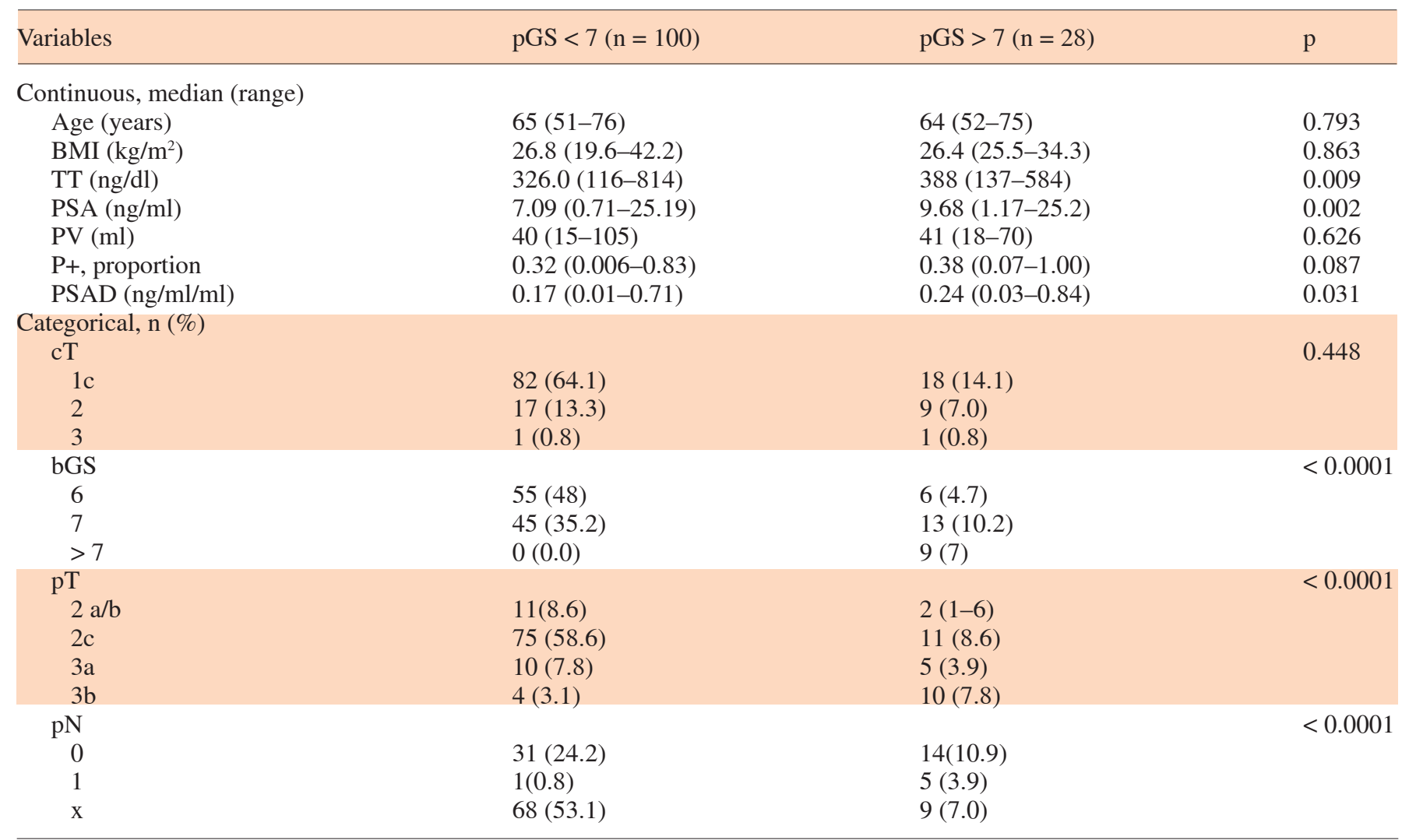

$\mathrm{BMI}=$ Body mass index $; \mathrm{TT}=$ total testosterone $; \mathrm{PSA}=$ prostate specific antigen $; \mathrm{PV}=$ prostate volume P+ = proportion of biopsy positive cores; PSAD = PSA density; $\mathrm{cT}=$ clinical tumour stage; $\mathrm{bGS}=$ biopsy Gleason score; $\mathrm{pT}=$ pathologic tumour stage; $\mathrm{pN}=$ pathologic nodal stage; pGS = pathologic Gleason score.

Simultaneous pretreatment serum samples of TT and PSA were obtained from a cubital vein, at least 1 month after TRUS biopsy, between 8:00-8:30 a.m. All samples were analyzed at our laboratory. The plasma levels of TT (normal range 18-758 ng/ dl) and PSA (normal range $0.2-4.0 \mathrm{ng} / \mathrm{ml}$ ) were determined by radioimmunoassay.

The prostatectomy specimens were fixed in total overnight (10\% neutral buffered formaldehyde), coated with India ink, and then weighed. Tissue sections of $4 \mu \mathrm{m}$ were prepared in standard fashion and stained with hematoxylin and eosin. Patients were classified according to primary tumor stage, lymph node, and metastatic status, using the American Joint Committee on Cancer TNM (2010) classification system. Seminal vesicle invasion was defined as tumor involvement of the muscular wall (pT3b). Bladder neck invasion was staged as pT3a. Surgical margins were stated as free (R0) or involved by cancer (R1). Tumors were graded according to the Gleason grading system and pGS was computed after summing up the two patterns, prevalent and secondary, of the tumor. High grade PCa was defined as $\mathrm{pGS}>7$. The variables were grouped as clinical (age, BMI, PSA, TT, PV, PSAD, bGS, and $\mathrm{P}+$ ) and pathologic (pGS, pT, surgical margins, and $\mathrm{pN}$ ).

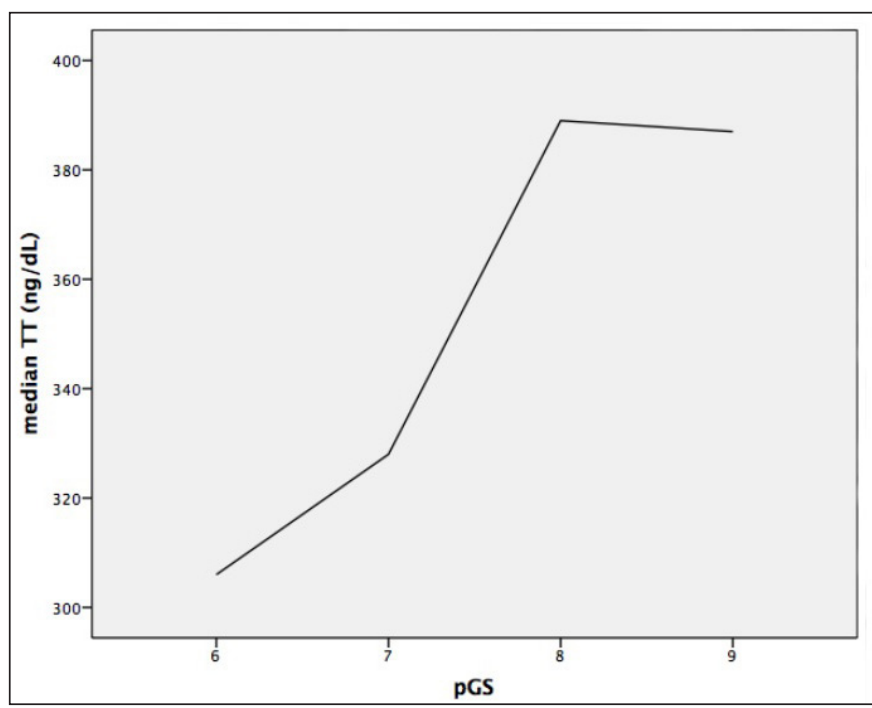

Fig. 1. Median plasma levels of TT as a function of the pGS. 
Table 3. Associations of high grade PCA with clinical and pathologic (pT) variables by logistic regression models

\begin{tabular}{|c|c|c|c|c|c|c|}
\hline \multirow[t]{2}{*}{ Variables } & \multirow{2}{*}{$\begin{array}{l}\text { Regression } \\
\text { coefficient }\end{array}$} & \multirow[t]{2}{*}{ Standard error } & \multirow[t]{2}{*}{ Odds ratio } & \multicolumn{2}{|c|}{$95 \%$ Confidence interval } & \multirow{2}{*}{$\mathrm{p}$} \\
\hline & & & & Standard error & Odds ratio & \\
\hline \multicolumn{7}{|c|}{ Univariate model } \\
\hline TT & 0.004 & 0.02 & 1.004 & 1 & 1.007 & 0.04 \\
\hline PSAD & 2.65 & 1.23 & 14.39 & 1.27 & 163.102 & 0.031 \\
\hline $\mathrm{bGS}>6$ & 1.5 & 0.503 & 4.481 & 1.674 & 12 & 0.003 \\
\hline $\mathrm{pT}>2$ & 1.948 & 0.476 & 7.088 & 2.788 & 18.02 & $<0.0001$ \\
\hline $\mathrm{TT}$ & 0.004 & 0.002 & 1.004 & 1 & 1.008 & 0.041 \\
\hline PSA & 0.175 & 0.064 & 1.191 & 1.05 & 1.351 & 0.006 \\
\hline PSAD & -2.076 & 2.136 & 0.125 & 0.002 & 8.25 & 0.331 \\
\hline $\mathrm{bGS}>6$ & 1.609 & 1.025 & 5 & 1.695 & 14.748 & 0.004 \\
\hline
\end{tabular}

$\mathrm{TT}=$ Total testosterone PSA = prostate specific antigen PSAD = PSA density $; \mathrm{pT}=$ pathologic tumour stage bGS = biopsy Gleason score.

\section{Statistical Methods}

The entire cohort, assessed by continuous and categorical variables, was classified into two groups according to the pGS that included low-intermediate (pGS 6-7) and high grade (pGS > 7) cases. Data on continuous variables are presented as medians with their respective ranges. Differences between groups were analyzed with the Mann-Whittney $U$ test.

Data on categorical variables are presented as proportions, and differences between groups were analyzed with Pearson's chisquared or Fisher's exact test as appropriate.

The associations of high grade PCa was investigated by the logistic regression model in which all variables were entered as continuous variables except for cT (cT1c vs. $\geq$ cT2), bGS (6 vs. $\geq$ 7 ), and pT (pT2 vs. pT3). All tests were two-sided with $\mathrm{p}<0.05$ considered to indicate statistical significance.

\section{Results}

The present analysis relates to 128 patients who met our inclusion criteria.

Clinical and pathologic characteristics of the study cohort are reported in table 1 which shows that the median plasma level of PSA was $7.5 \mathrm{ng} / \mathrm{ml}$ and TT was $331.5 \mathrm{ng} /$ dl. The cohort showed a median age of 64.5 years with a median BMI of $26.7 \mathrm{~kg} / \mathrm{m}^{2}$. Radical prostatectomy was performed by RARP in $98(76.6 \%)$ cases and associated with extended lymph node dissection in 49 (38.3\%) patients.

The clinical stage was cT1c in $100(78.1 \%)$ cases and $\geq$ cT2 in $28(21.9 \%)$ patients. Tumor grade was detected as bGS $>7$ in $9(7.0 \%)$ and pGS $>7$ in $28(21.8 \%)$ of pa-

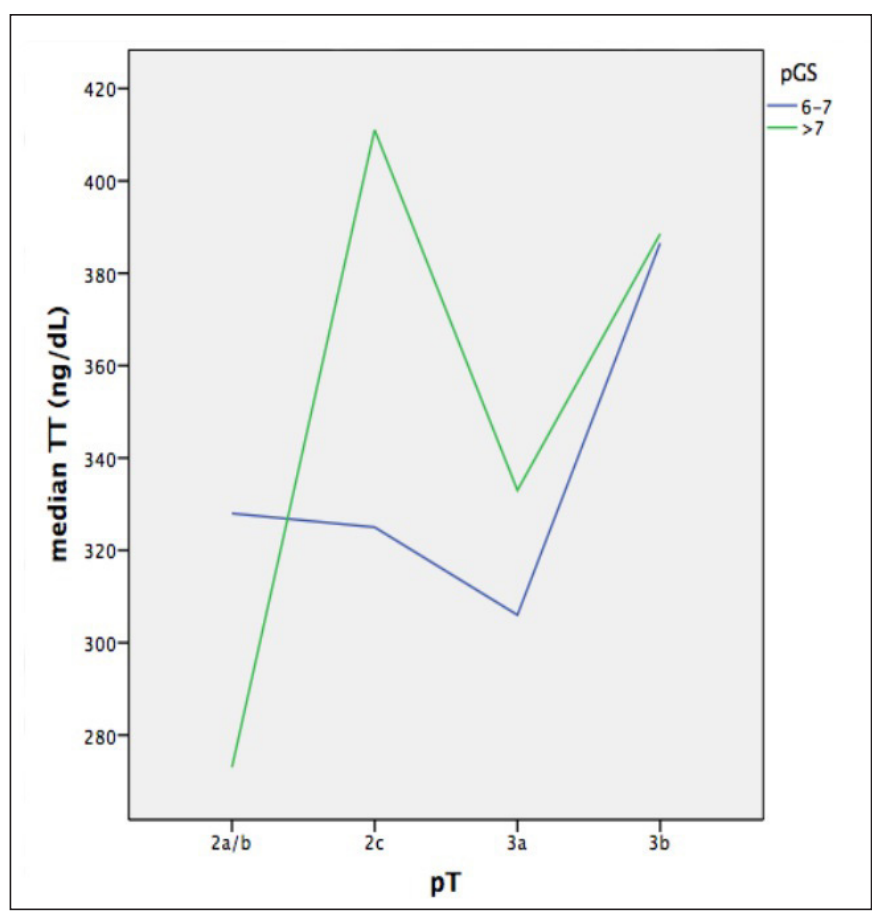

Fig. 2. Median TT plasma levels as a function of $\mathrm{pT}$ and stratified by $\mathrm{pGS}$.

tients. Prostate cancer was organ confined in $99(77.4 \%)$ cases. Lymph node metastases were detected in 6 patients $(4.7 \%$ of the entire cohort). 


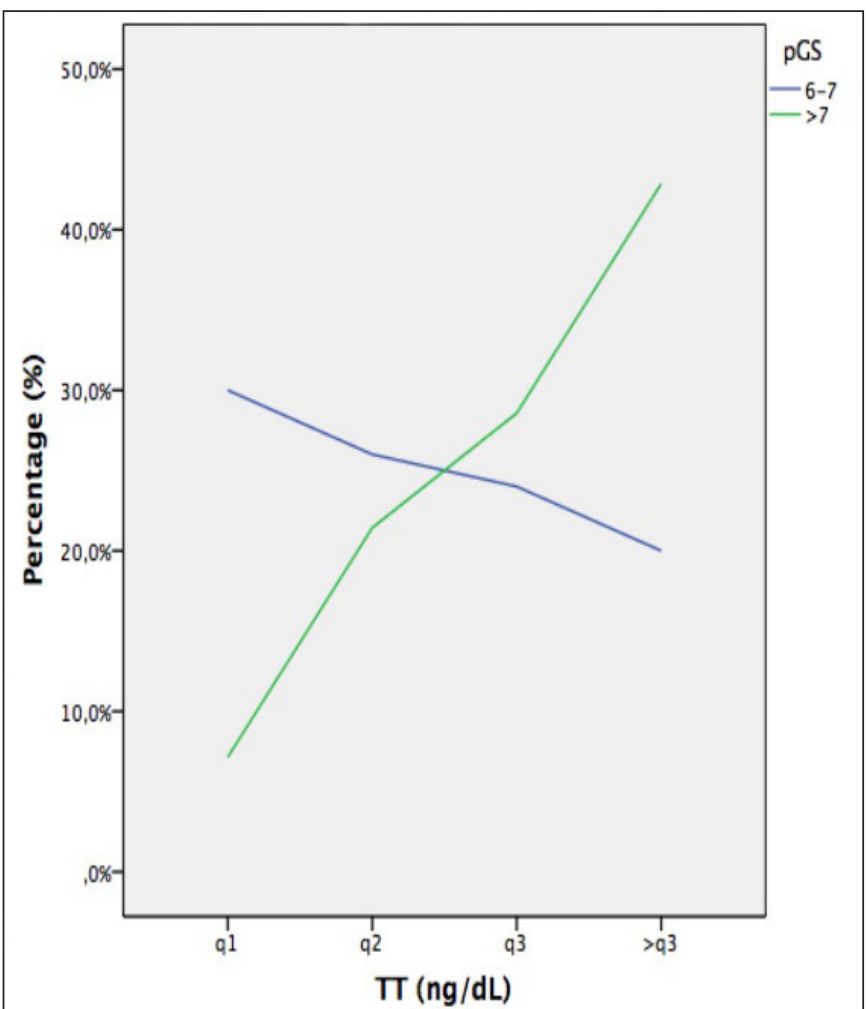

Fig. 3. The distribution of TT quartiles as percentage and stratified by the pGS in the study cohort. Legend: q1, TT $<266.5 \mathrm{ng} / \mathrm{dL} ; \mathrm{q} 2$, $266.5 \leq \mathrm{TT}<331.5 \mathrm{ng} / \mathrm{dL} ; \mathrm{q} 3,331.5 \leq \mathrm{TT}<408.25 \mathrm{ng} / \mathrm{dL} ; \mathrm{q} 4$, $\mathrm{TT} \geq 408.25 \mathrm{ng} / \mathrm{dL}$.

Table 2 shows the clinical and pathological variables that associate with low-intermediate tumors ( $\mathrm{pGS}<7, \mathrm{n}$ $=100$ ) vs. high grade cancers ( $\mathrm{pGS}>7, \mathrm{n}=28$ ). Higher median plasma levels of TT and PSA positively associated with high grade PCA that showed lower rates of bGS 6, higher rates of pT3b, and metastatic (pN1) disease. The PSAD was significantly higher in high grade $\mathrm{PCa}$, but there were no differences by age, BMI, PV, P+, and $\mathrm{cT}$.

Table 3 reports the associations of high grade $\mathrm{PCa}$ with the clinical and pathological variables as assessed by logistic regression models. The analysis excluded the factors which were unrelated to high grade prostate cancer. In the univariate model, the variables that associated with pGS $>7$ were TT $(\mathrm{p}=0.040)$, PSA $(\mathrm{p}=0.002)$, PSAD $(\mathrm{p}=0.031), \mathrm{bGS}>6(\mathrm{p}=0.003)$, and $\mathrm{pT}>2(\mathrm{p}<$ $0.0001)$. In the clinical multivariate model, independent and positive predictors of $\mathrm{pGS}>7$ were TT $(\mathrm{p}=0.041$; OR $=1.004)$, PSA $(p=0.006 ;$ OR $=1.191)$, and bGS $>$ $6(\mathrm{p}=0.004 ; \mathrm{OR}=5.0)$. So far, the model suggests that the change in the log-odds of pGS $>7$ by just one unit increase in TT plasma levels is 1.004, which means that one unit increase in TT plasma levels, evaluated as a continuous variable, increases the odds of high grade PCa by $4 \%$. The independent association between TT and pGS is depicted in figure 1 which shows that increasing median levels of TT directly relate to increasing pGS.

The independent associations between TT and pGS as well as pT are illustrated in figure 2 which shows that median TT plasma levels directly relates to both pT and pGS; moreover, differences of TT median plasma levels tend to decrease as disease extends beyond the prostate (pT3b).

Figure 3 shows the distribution of TT plasma levels by quartiles as percentage and stratified by pGS in the cohort of patients. The stratification by quartiles is as follows: q1, TT < $266.5 \mathrm{ng} / \mathrm{dl} ; \mathrm{q} 2,266.5 \leq \mathrm{TT}<331.5 \mathrm{ng} /$ dl; q3, $331.5 \leq \mathrm{TT}<408.25 \mathrm{ng} / \mathrm{dl}$; and $\mathrm{q} 4$, TT $\geq 408.25$ $\mathrm{ng} / \mathrm{dl}$. As shown, the distributions of TT plasma levels are directly increasing in the high grade group and decreasing in the low-intermediate grade cluster; moreover, there is an interaction effect between q2 and q3.

There is evidence that the distribution of preoperative TT plasma levels clusters two different populations in the study cohort of patients who have been stratified according to the pGS in low-intermediate and high grade PCa.

\section{Discussion}

The preoperative association between TT plasma levels and pGS is a subject that has long been investigated; likewise, the topic still remains controversial and unsettled [30]. Indeed, it has been shown that TT might both associate $[18,20,27]$ or not associate $[17,23,24]$ with tumor grade; however, if any association has been found, both lower $[18,20,27,33,34]$ as well as higher TT plasma levels [30-32, 35, 36] have been detected in high grade PCa. In a contemporary cohort of patients, our study showed that preoperative TT plasma levels associated with high grade $\mathrm{PCa}$ as assessed in prostatectomy specimens. In the clinical multivariate logistic regression modem, TT was an independent covariate predicting high grade $\mathrm{PCa}$; so far, the model suggests that the change in the log-odds of pGS $>7$ by just one unit increase in TT plasma levels is 1.004 which means that one unit increase in TT plasma levels, evaluated as a continuous variable, increases the odds of high grade PCa by $4 \%$. The independent and positive predictive potential of TT is outlined in figures 1 and 2 . The pres- 


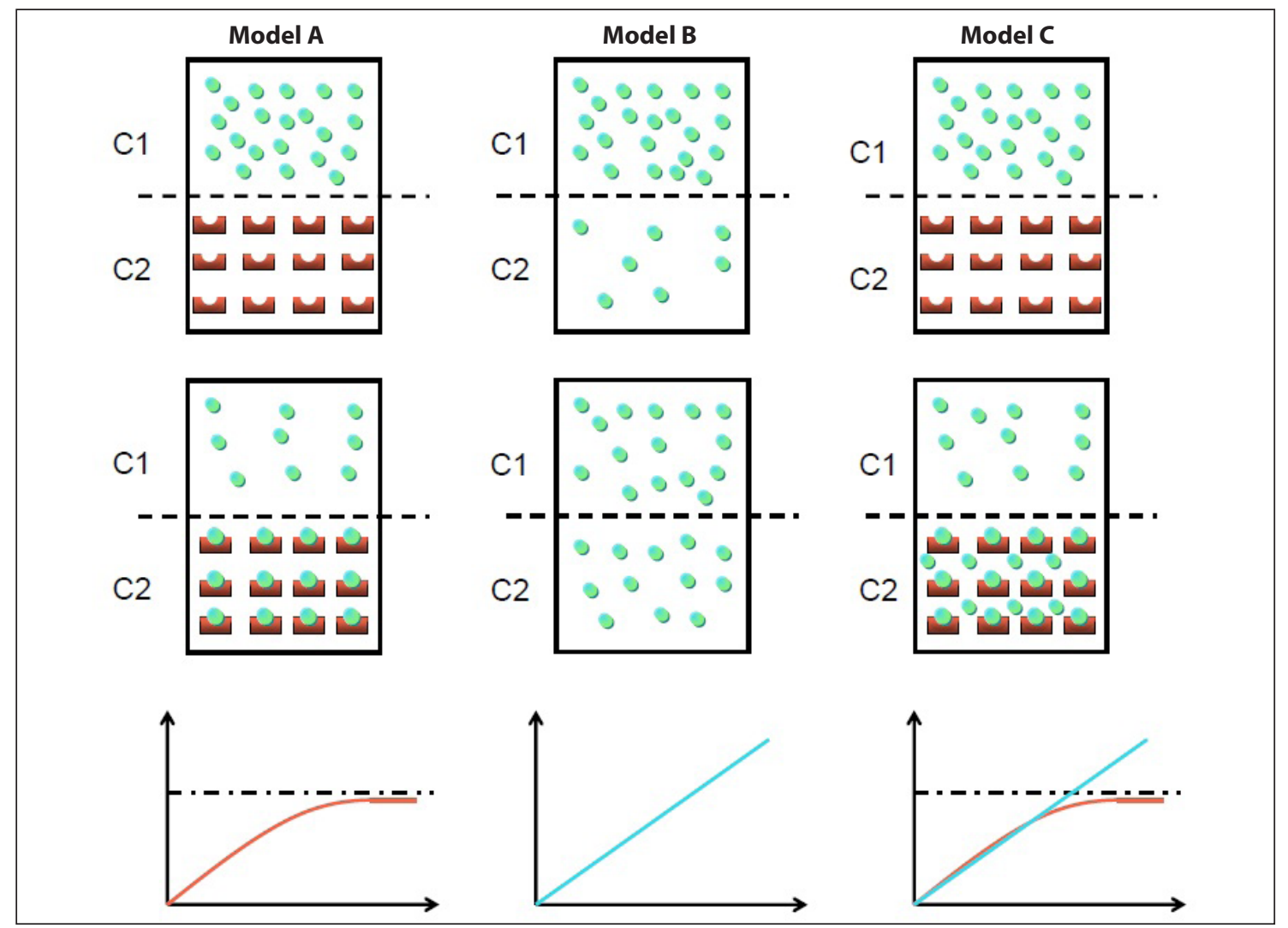

Fig. 4. The diffusion models explaining the sensitivity of high grade tumors to increased serum levels of TT. Low-intermediate cancers associate with model A in which the diffusion of TT from the blood (C1) to the prostate $(\mathrm{C} 2)$ compartments is limited by the process of binding receptor saturation. High grade PCA associates with model $\mathrm{B}$ in which the diffusion between $\mathrm{C} 1$ and $\mathrm{C} 2$ is directly proportional to TT. Intermediate-high grade PCA associate with mode $\mathrm{C}$ which is a combination of models $\mathrm{A}$ and $\mathrm{B}$. The diffusion curves of each model are also reported (for details see the discussion section).

ent investigation confirms our previous results that have been detected in a preceding cohort of patients in whom preoperative TT was an independent factor associated with high grade PCa along the pituitary-testis-prostate axis [37]. Although our findings contradict studies demonstrating that lower TT associates with high grade PCa $[18,20,27]$, there is a study which shows that both the lowest and the highest circulating serum levels of TT associated with high grade PCa, and the relationship is depicted by a nonlinear U-shaped curve risk relationship [38]. The results of our study relate to the finding of two investigations showing that higher levels of free testosterone, which is highly correlated to TT, associated with an increased risk of aggressive PCa among older men $[39,40]$. Although serum TT decline with advancing age, it is well known that the incidence of PCa steadily increases. Our investigation showed that age did not have any confounding role in predicting pGS.

It has been shown that TT is metabolized within the prostate to dihydrotestosterone (DHT) by the enzyme 5-alpha-reductase, and DHT is the major intracellular androgen that promotes growth within the prostate [41]. It has also been demonstrated that preoperative DHT serum levels significantly decreased after RP suggesting the evidence of a functional dependence between TT and $\mathrm{PCa}$ along the pituitary-testis-prostate axis $[4,5]$. Our clinical multivariate model (table 3 ) relate to androgen hormonal dynamics that have been reported after RP $[4$, 5]. It has been suggested that there is a limit to the ability of androgens to stimulate PCa growth, and it has been proposed, based on androgen receptor (AR) binding evidence, the theoretical saturation model that limits the 
ability of androgens to stimulate PCa growth [42]. As a consequence of this theory, PCa growth is sensitive to plasma levels of TT at or below the near castrate range and becomes insensitive to TT variations above this level [41]. The results of our study and the evidence from our clinical model do not fit with the former proposed model (table 3; fig. 1-3). As a theory supported by the results of the present study, we introduce the diffusion model that might explain why high grade PCa may be sensitive to increased plasma levels of TT. As shown in figure 4, models A, B, and C are introduced. Low-intermediate grade tumors associates with model $\mathrm{A}$ in which the diffusion of TT from the blood $(\mathrm{C} 1)$ to the prostate $(\mathrm{C} 2)$ compartments is limited by the process of binding receptor saturation; as a result, lower levels of TT are needed.

High grade $\mathrm{PCa}$ associates with model $\mathrm{B}$ in which the diffusion between $\mathrm{C} 1$ and $\mathrm{C} 2$ is directly proportional to TT of which higher plasma levels are required. Intermediate-high grade $\mathrm{PCa}$ associate with mode $\mathrm{C}$ which is a combination of models A and $\mathrm{B}$; indeed, although binding receptors might be saturated, increased plasma levels of TT penetrate into the cytoplasm of prostate cancer cells in which the hormone exhibits its effects without needing to bind to AR. Figure 4 also shows the diffusion curves of each model in which the plasma levels of TT in the prostate compartment (c2) is a function of time. In model A, the diffusion is limited by the saturation of the receptors that is induced by c 2 max value. In model $\mathrm{B}$, the diffusion is directly proportional to the plasma concentration of TT, expressed by a straight line, and not inhibited by the saturation phenomena. The saturation curves both coexist in model $\mathrm{C}$ that may indicate a dual $\mathrm{PCa}$ population in which coexist both intermediate and high grade tumors. A dual PCa population is also suggested by figure 3 which shows that the distributions of TT plasma levels are directly increasing in the high grade group and decreasing in the low-intermediate grade cluster; moreover, there is an interaction effect between q2 and $\mathrm{q} 3$. As a result, the evidence of the study suggests that the distribution of preoperative TT plasma levels identifies two different populations in the study cohort of patients who have been stratified according to the pGS in low-intermediate and high grade PCa.

The results of our clinical model suggest that independent TT dynamics related to different grades of PCa might have important applications when looking forward to the natural history of $\mathrm{PCa}$ progressing to castration resistance for planning modern target therapies by both inhibitors of androgen synthesis, such as abiraterone, AR antagonists, such as MDV3100, or 5-alpha-reductase inhibitors, such as dutasteride [43].
There are several limitations to the present investigation. First, although the data were collected prospectively, it was analyzed retrospectively.

Second, is the sample size of the population and the lack of confirmatory studies showing a strong methodology for detecting associations between plasma levels of TT and tumor grade.

Third, to measure serum TT levels, gas chromatography-mass spectrometry was not used, which is considered the gold standard in assessing TT serum levels, and pretreatment serum levels of DHT measurements were not computed.

Fourth, although there were only 28 cases with pGS $>7$ which represents $21.8 \%$ of the cohort, the group that was classified by $\mathrm{pGS}>7$ was really the high grade group of the cohort according to the new classification system of PCa that has been proposed by the International Society of Urologic Pathology Consensus Conference [44]. However, the present study, while progressing, will have important and useful clinical applications on tumor upgrading in low-intermediate clinical risk prostate cancer classes.

In summary, we have determined that preoperative plasma levels of TT directly and independently associate with pathology-detected high grade $\mathrm{PCa}$ in a contemporary cohort of patients. Pretreatment baseline plasma levels of TT, which is an independent factor assessing tumor grade, might have clinical applications for managing PCa. New and well designed prospective studies dealing with this subject are required. 


\section{References}

1 Huggins C, Hodges CV: Studies on prostate cancer. I: The effect of castration, of estrogen and of androgen injection on serum phosphatases in metastatic carcinoma of the prostate. Cancer Res 1941;1:293-297.

2 Stamey TA, Yang N, Hay AR, McNeal JE, Freiha FS, Redwine E: Prostate-specific antigen as a serum marker for adenocarcinoma of the prostate. N Engl J Med 1987;317:909916.

3 Armbruster DA: Prostate-specific antigen: biochemistry, analytical methods, and clinical application. Clin Chem 1993;39:181-195.

4 Miller LR, Partin AW, Chan DW, Bruzek DJ, Dobs AS, Epstein JI, Walsh PC: Influence of radical prostatectomy on serum hormone levels. J Urol 1998;160:449-453.

5 Olsson M, Ekstrom L, Schulze J, Kjellman A, Akre O, Rane A, Gustafsson: Radical prostatectomy: influence on serum and urinary androgen levels. Prostate 2010;70:200-205.

6 Harper ME, Pierrepoint CG, Griffiths K: Carcinoma of the prostate: relationship of pretreatment hormone levels to survival. Eur J Cancer Clin Oncol 1984;20:477-482.

7 Chen SS, Chen KK, Lin AT, Chang YH, Wu $\mathrm{HH}$, Chang LS: The correlation between pretreatment serum hormone levels and treatment outcome for patients with prostatic cancer and bony metastasis. BJU Int 2002;89: 710-713.

8 Hammond GL, Kontturi M, Maattala P, Puukka M, Vihko R: Serum FSH, LH and prolactin in normal males and patients with prostatic diseases. Clin Endocrinol (Oxf) 1977;7: 129-135.

9 Kumar VL, Wadhwa SN, Kumar V, Farooq A: Androgen, estrogen, and progesterone receptor contents and serum hormone profiles in patients with benign hypertrophy and carcinoma of the prostate. J Surg Oncol 1990;44: $122-128$.

10 Hilz H, Graefen M, Noldus J, Hammerer P, Knabbe C, Huland E, Huland H: Advanced prostate cancer is associated with a decrease in serum luteinizing hormone. Eur Urol 2000;38:243-249.

11 Madersbacher S, Shatzl G, Bieglmayer C, Reiter BW, Gassner C, Berger P, Zidek T, Marberger M: Impact of radical prostatectomy and TURP on the hypothalamic-pituitary-gonadal axis. Urology 2002;60:869-874.

12 Fodstad P, Bjoro T, Torlakovic G, Fossa SD: No association of serum gonadal or pituitary hormone with prognostic parameters in stages $\mathrm{T} 1$ to $\mathrm{T} 3 \mathrm{pN} 0 \mathrm{M} 0$ prostate cancer. $\mathrm{J}$ Urol 2002;168:1188-1192.

13 Pound CR, Partin AW, Eisenberger M, Chan DW, Pearson JD, Walsh PC: Natural history of progression after PSA elevation following radical prostatectomy. JAMA 1999;281: 1591-1597.

14 Hull GW, Rabbani F, Abbas FA, Wheeler
TM, Kattan MW, Scardino PT: Cancer control with radical prostatectomy alone in 1,000 consecutive patients. J Urol 2002;167:528534.

15 Freedland SJ, Humphreys EB, Mangold LA, Eisenberger M, Dorey FJ, Walsh PC, Partin AW: Risk of prostate cancer-specific mortality following biochemical recurrence after radical prostatectomy. JAMA 2005;294:433439.

16 Cuzick J, Fisher G, Kattan MW, Berney D, Oliver T, Foster CS, Moller H, Reuter V, Fearn P, Eastham J, Scardino P: Long-term outcome among men with conservatively treated localised prostate cancer. Br J Cancer 2006;95:1186-1194.

17 Monda JM, Myers RP, Bostwick DG, Oesterling JE: The correlation between serum prostate-specific antigen and prostate cancer is not influenced by the serum testosterone concentration. Urology 1995;46:62-64.

18 Ide H, Yasuda M, Nishio K, Saito K, Isotani S, Kamiyama Y, Muto S, Horie S: Development of a nomogram for predicting high-grade prostate cancer on biopsy: the significance of serum testosterone levels. Anticancer Res 2008;28:2487-2492.

19 Anderson SO, Adami HO, Bergstrom R, Wide B: Serum pituitary and sex steroid hormone levels in the etiology of prostatic cancer - a population-based case control study. Br J Cancer 1993;68:97-102.

20 Schatzl G, Madersbacher S, Thurridl T, Waldmuller J, Kramer G, Haitel A, Marberger M: High-grade prostate cancer is associated with low serum testosterone levels. Prostate 2001; 47:52-58.

21 Severi G, Morris HA, MacInnis RJ, English DR, Tilley W, Hopper JL, Boyle P, Giles GG: Circulating steroid hormones and the risk of prostate cancer. Cancer Epidemiol Biomarkers Prev 2006;15:86-91.

22 Mikkola AK, Aro JL, Rannikko SA, Salo JO: Pretreatment plasma testosterone and estradiol levels in patients with locally advanced or metastatized prostate cancer. FINNPROSTATE group. Prostate 1999;39:175-181.

23 Salonia A, Gallina A, Briganti A, Suardi N, Capitanio U, Abdollah F, Bertini R, Freschi M, Rigatti P, Montorsi: Circulating estradiol, but not testosterone is a signficant predictor of high-grade prostate cancer in patients undergoing radical prostatectomy. Cancer 2011; 117:5029-5038.

24 Sher DJ, Mantzoros C, Jacobus S, Regan MM, Lee GS, Oh WK: Absence of relationship between steroid hormone levels and prostate cancer tumor grade. Urology 2009; 73:356-361.

25 Takizawa I, Nishiyama T, Hara N, Isahaya E, Hoshii T, Takahashi K: Serum prostate specific antigen levels reflect the androgen milieu in patients with localized prostate cancer receiving androgen deprivation therapy: tumor malignant potential and androgen milieu. Prostate 2010;70:1935-1401.

26 Hoffman MA, DeWolf WC, Morgentaler A: Is low serum free testosterone a marker for high grade prostate cancer? J Urol 2000;163: 824-827.

27 Zhang PL, Rosen S, Veeramachaneni R, Kao J, DeWolf WC, Bubley G: Association between prostate cancer and serum testosterone levels. Prostate 2002;53:179-182.

28 Lane BR, Stephenson AJ, Magi-Galluzzi C, Lakin MM: low testosterone and risk of biochemical recurrence and poorly differentiated prostate cancer at radical prostatectomy. Urology 2008;72:1240-1245.

29 Kratzik C, Womastek I, Bieglmayer C, Schatzl G, Lackner J, Freibauer C, Lunglmayr G: Lower serum total testosterone is associated with lymph node metastases in radical prostatectomy cohort study. Anticancer Res 2011;31:3615-3618.

30 Klap J, Schmid M, Loughlin KR: The relationship between total testosterone levels and prostate cancer: a review of the continuing controversy. J Urol 2015;193:403-414.

31 Porcaro AB, Petrozziello A, Ghimenton C, Migliorini F, Sava T, Caruso B, Cocco C, Romano M, Cavalleri S, Artibani W: Serum total testosterone is a significant preoperative variable independently contributing to separating the prostate cancer population into prostatectomy Gleason score groups. Urol Int 2013;91:55-61.

32 Porcaro AB, Petrozziello A, Ghimenton C, Migliorini F, Sava T, Caruso B, Romano M, Cavalleri S, Artibani W: Associations of pretreatment serum total testosterone measurements with pathology-detected Gleason score cancer. Urol Int 2014;93:269-278.

33 Dai B, Qu Y, Kong Y, Ye D, Yao X, Zhang S, Wang C, Zhang H, Yang W: Low pretreatment serum total testosterone is associated with a high incidence of Gleason score 8-10 disease in prostatectomy specimens: data from ethnic Chinese patients with localized prostate cancer. BJU Int 2012;110:E667-E672.

34 Mearini L, Zucchi A, Nunzi E, Villirillo T, Bini V, Porena M: Low serum testosterone levels are predictive of prostate cancer. World J Urol 2013;31:247-252.

35 Salonia A, Abdollah F, Capitanio U, Gallina A, Suardi N, Briganti A, Zanni G, Ferrari M, Castiglione F, Clementi MC, Rigatti P, Montorsi F: Preoperative sex steroids are significant predictors of early biochemical recurrence after radical prostatectomy. World J Urol 2013;31:275-280.

36 Imamoto T, Suzuki H, Akakura K, Komiya A, Nakamachi H, Ichikawa T, Igarashi T, Ito H: Pretreatment serum level of serum testosterone as a prognostic factor in Japanese men with hormonally treated stage D2 prostate cancer. Endocr J 2001;48:573-578. 
37 Porcaro AB, Petrozziello A, Ghimenton C, Migliorini F, Sava T, Caruso B, Cocco C, Romano M, Artibani W: Along the pituitarytestis-prostate axis, serum total testosterone is a significant preoperative variable independently contributing to separating the prostate cancer population into prostatectomy Gleason score groups. Anticancer Res 2012;32: 5015-5022.

38 Salonia A, Abdollah F, Capitanio U, Suardi N, Briganti A, Gallina A, Colombo R, Ferrari M, Castagna G, Rigatti P, Montorsi F: Serum sex steroids depict a nonlinear U-shaped association with high-risk prostate cancer at radical prostatectomy. Clin Cancer Res 2012; 18:3648-3657.
39 Pierorazio PM, Ferrucci L, Kettermann A, Longo DL, Metter EJ, Carter HB: Serum testosterone is associated with aggressive prostate cancer in older men: results from the Baltimore Longitudinal Study of Aging. BJU Int 2010;105:824-829.

40 Albisinni S, De Nunzio C, Tubaro A, Barry WT, Banez LL, Freedland SJ: Greater percent-free testosterone is associated with highgrade prostate cancer in men undergoing prostate biopsy. Urology 2012;80:162-168.

41 Ghanadian R, Puah CM, O’Donoghue EP: Serum testosterone and dihydrotestosterone in carcinoma of the prostate. Br J Cancer 1979;39:696-699.
42 Morgentaler A, Traish AM: Shifting the paradigm of testosterone and prostate cancer: the saturation model and the limits of androgen-dependent growth. Eur Urol 2009;55: 310-320.

43 Corcoran NM, Gleave ME: Targeted therapy in prostate cancer. Histopathology 2012;60: 216-231.

44 Epstein JI, Egevad L, Amin MB, Delahunt B, Srigley JR, Humphrey PA: The 2014 International Society of Urologic Pathology (ISUP) Consensus Conference on Gleason grading of prostate carcinoma: definition of grading pattern and proposal for a new grading system. Am J Path 2016;40:244-252. 